\title{
DInSAR Estimation of Land Motion Using Intermittent Coherence With Application to the South Derbyshire and Leicestershire Coalfield
}

\author{
ANDREW SOWTER ${ }^{1}$, LUKE BATESON ${ }^{2}$, POUL STRANGE ${ }^{2}$, KEITH \\ AMBROSE $^{2}$, MOH. FIFIK SYAFIUDIN ${ }^{1}$ \\ ${ }^{1}$ NGI, University of Nottingham, Nottingham NG7 2TU, UK \\ ${ }^{2}$ British Geological Survey, Keyworth, Nottinghamshire NG12 5GG
}

(Received 20 March 2013; in final form Day Month Year)

\begin{abstract}
Differential interferometric synthetic aperture radar (DInSAR) is a recognized remote sensing method for measuring the land motion occurring between two satellite radar acquisitions. Advanced DInSAR techniques such as persistent scatterers (PS) and small baseline methods are excellent over urban and rocky environments but generally poor over more rural and natural terrain where the signal can be intermittently good and bad. Here, we describe the ISBAS (Intermittent Small Baseline Subset) method, which appears to improve results over natural, woodland and agricultural terrain. This technique uses a multilooked, low-resolution approach, which is particularly suitable for deriving the linear components of subsidence for large-scale deformations. Application of the ISBAS method over a coal mining area in the UK indicates that it is able to significantly improve upon a standard small baseline approach.
\end{abstract}

\section{Introduction}

The Small Baseline Subset (SBAS) method (Berardino et al., 2002; Lanari et al., 2007) is a small baseline technique that uses stacks of differential interferometric synthetic aperture radar (DInSAR) observations of the same location to estimate slow linear and non-linear motion of the land surface to millimetric precision. The method, especially when using multilooked, low-pass interferograms, is relatively easy to implement and is excellent for the investigation of large spatial scale distortions. However, SBAS is generally limited to urbanized and rocky landscapes where the coherence is sufficiently high. This often means that only an incomplete picture of the deformation pattern is visible which may lead to poor interpretation and, in remote areas, deformation may not be detected at all. The extent of this may differ slightly from sensor-to-sensor as the coherence of rural classes, such as agricultural fields and forest stands, improves with longer wavelengths. However, the limitations of the technique are fairly consistent in that urban and rocky landscapes provide the most consistent sources of coherence over large image stacks whatever the radar frequency. This paper extends the SBAS technique to estimate land motion measurements across a wider range of land cover classes than are normally possible.

The SBAS method begins with a stack of coregistered synthetic aperture radar (SAR) images and forms differential interferograms between any two pairs as long as the orbital baseline is low. Principally, this is because a small baseline mitigates against low coherence and minimizes the effect of a poor interferogram simulation, required for DInSAR. The components of the line-of-sight motion are formed only for those points that are consistently coherent in all interferograms, which tend to be in urban or rocky areas where there is a dominance of brightly reflecting targets that do not change from image-to-image. In contrast, a vegetated region in a temperate zone is subject to many changes in land cover, soil moisture, weather conditions and agricultural activity, any of which may suddenly alter the physical characteristics of 


\section{A. Sowter et al.}

the surface between observations, losing the coherence (Ferretti et al., 2003). The high dynamics in such regions mean that it is likely that such targets will appear intermittently coherent meaning they have high coherence in some interferograms but not in others. Thus, there may still be highly coherent interferometric measurements within the stack of SAR data that are currently excluded from an SBAS analysis. There have been no attempts to adapt small baseline algorithms to use these values, although the intermittent coherence approach has been applied to the stacking of interferograms to improve the estimation of the linear velocity of very largewavelength deformations in a remote area (Biggs et al., 2007).

The purpose of this paper is to adapt an SBAS method to use the intermittent coherence of areas in order to increase the number and distribution of point measurements of land deformation. The method, termed here the ISBAS (Intermittent Small Baseline Subset) method, is simple to apply and significantly improves the capability to examine rural and vegetated areas. The basic algorithm for the derivation of low-pass linear deformation from multilooked data is described and demonstrated over a coal mining area in the UK where a dramatic improvement in coverage is seen when compared to a standard SBAS analysis.

\section{Methodology}

The ISBAS algorithm described here is based upon the low-pass SBAS method described by Berardino et al. (2002). The SBAS method therefore begins with lowresolution, multilooked, interferograms that are then individually phase unwrapped. The points that are unwrapped are those for which the average coherence across all interferograms is above a set threshold. The ISBAS method proposed here considers each interferogram separately, selecting and unwrapping pixels with high coherence in that layer only. If $(i, j)$ are the row and column coordinates of the point in the multilooked master image, the following equation is then solved to estimate the linear velocity $V_{i j}$ and height error $\delta h_{i j}$ at each point:

$$
\Phi_{i j}=\frac{4 \pi}{\lambda}\left(\delta t_{k} V_{i j}+\frac{B_{\perp}^{i j k}}{R_{i j} \sin \theta_{i j}} \delta h_{i j}\right)
$$

where $\Phi_{i j k}$ is the unwrapped interferogram phase for the $k^{\text {th }}$ interferogram, $\lambda$ is the radar wavelength, $\delta t_{k}$ is the time difference, $B_{\perp}^{i j k}$ is the perpendicular baseline, $R_{i j}$ is the slant-range to the target and $\theta_{i j}$ is the incidence angle of the radar with the gravity normal.

There are specific conditions on the selection of points $(i, j)$ and layers $(k)$. For any $(i, j)$, only those layers, $k$, for which there exists an unwrapped phase (pixels with high coherence) are used. The number used, $m$, will differ from point to point. Furthermore, only those point coordinates $(i, j)$ for which $m>M$, where $M$ is some threshold, are used in the analysis. The value of the threshold $M$ selected is based on two criteria: maximizing $M$ to reduce uncertainty in the solution; and minimizing $M$ to increase the spatial distribution of points. The final selection of the threshold is a trade-off between these two properties. A solution that closely matches the SBAS solution would be to set $M$ as a large number, close to the number of small baseline interferograms. However, it is unlikely that this would result in any improvement in the number and distribution of points and therefore smaller values of $M$ are considered. 
In this paper, a multilooked, low-pass approach is applied. This is because the land deformation detected in this paper is geological in nature and of a very large scale extending over many hundreds of meters, if not kilometers. Thus, the benefits of a full-resolution analysis would be negligible and at the cost of a much heavier computational overhead.

Over agricultural and other vegetated areas, coherence is so dynamic that high coherence is maintained primarily from pairs of images within the same season, with short temporal baselines. Therefore, the ISBAS technique is optimized when there is a good, regular, set of acquisitions without large gaps in the temporal sequence.

\section{Demonstration over the South Derbyshire and Leicestershire Coalfield}

\subsection{Land cover}

The area under consideration, (figure 1), falls mainly within two landscape areas of the UK, the Leicestershire and South Derbyshire coalfields and Charnwood Forest. Of these, Charnwood Forest is a unique landscape characterized by its Precambrian geology (Worssam and Old, 1988; Carney et al., 2001; Carney et al., 2002) that outcrops as rugged craggy hills, and areas of ancient woodland. The hills of Charnwood Forest are ideal for acid grassland, open heathland and bracken (Ambrose et al., 2012). Hay meadows and pastures rich in wildlife can be found in the valley bottoms. It is generally an area of mixed farming. Quarrying for building stone and aggregates has left a significant imprint on the landscape of Charnwood Forest. This area is host to a number of special sites of scientific interest (SSSIs) for their geological and biodiversity interests. Planting by The National Forest has increased the area of woodland; it now accounts for around $20 \%$ of the land in the study area.

$<<$ Figure 1 here $>>$

\subsection{The South Derbyshire and North West Leicestershire coalfields}

These coalfields consist of two northwest - southeast aligned 'lozenge -shaped' basins separated by the major Ashby anticline with a similar trend. Major northwest to southeast striking faults help define the coalfield. In particular, the Thringstone Fault marks the eastern boundary of the North West Leicestershire basin and the Boothorpe Fault defines the eastern limit of the South Derbyshire basin.

The South Derbyshire Coalfield extends from Burton upon Trent southeastwards through Swadlincote to Heather, a distance of approximately $15 \mathrm{~km}$, and the exposed part of the coalfield is roughly $5 \mathrm{~km}$ wide. The centre of this basin is occupied by the Pennine Middle Coal Measures Formation, which together with the underlying Pennine Lower Coal Measures Formation totals 620m in thickness (Carney et al., 2002). Up to 20 different seams, have been worked over more than 800 years, ranging in thickness from $0.6 \mathrm{~m}$ to $4.4 \mathrm{~m}$. There has been significant subsidence over wide areas of the coalfield, particularly following large scale longwall mining extraction methods after nationalization of the UK coal industry in 1947.

The North West Leicestershire Coalfield extends over $25 \mathrm{~km}$, averaging $7 \mathrm{~km}$ wide, centered on the town of Coalville. The eastern boundary, the Thringstone Fault, throws the Coal Measures strata against the Precambrian rocks of Charnwood Forest. Part of the Coalfield to the south of Coalville is concealed by up to $100 \mathrm{~m}$ of overlying Triassic strata (Strange et al., 2010). The total thickness of the Pennine Lower and Middle Coal Measures Formations is $340 \mathrm{~m}$. Horizontal or gently dipping strata, the absence of major faulting in the mined areas, and the consistency in seam quality and 


\section{A. Sowter et al.}

thickness allowed widespread mechanized mining of the coal, resulting in the coalfield achieving national records in output during the 1970s. In the last years of deep mining, between 1965 and 1991, the higher coal seams in the Pennine Middle Coal Measures were extensively worked between Coalville and Desford, creating widespread subsidence affecting many buildings, roads and other structures, altering the surface topography and modifying drainage patterns resulting in water-filled subsidence hollows.

Deep mining had ceased by 1991, but open cast coal working has continued in parts of the exposed coalfields, where the seams have been close enough to the surface to warrant extraction in deep excavations up to $120 \mathrm{~m}$ in depth.

Although mining in both basins had existed over a long time-span, with historical records dating back to 1204, the advent of steam pumping engines at the beginning of the 19th Century allowed large collieries to develop and workings to extend to greater depths (Owen, 1984). The density of mines and the widespread interconnections between different collieries ensured the mine water levels remained low, at depths of more than 250m across the two basins. The last mine to close in the South Derbyshire basin was Donisthorpe in 1990. In the Leicestershire basin, Bagworth Colliery was last to close in 1991. Once the mine pumps had been switched off, the mine water levels gradually rose, with reports of water reaching the surface north of Coalville in 1995 (Smith, 1996); springs started issuing mine water in the South Derbyshire basin around Cadley Hill in 2008 and Oakthorpe near Measham in 2009 (Bailey et al., 2011).

With the rise of groundwater through the old workings, resulting in the increase in pore water pressure, gradual uplift of the ground surface has been observed in a number of abandoned coalfields (Donnelly et al., 2007; Pottgens, 1985). Bekendam and Pottgens (1995) suggested the uplift amounted to between 2 and $4 \%$ of the maximum previously detected vertical subsidence.

A map of the coal measures and major faults in the area is shown in figure 1

\subsection{Satellite data}

The study used 32 descending SAR images of the site acquired by the European Space Agency (ESA) ENVISAT Advanced Synthetic Aperture Radar (ASAR) sensor acquired between June 2003 and February 2009. The distribution of acquisitions is relatively well spread over this period and is therefore suitable for the ISBAS technique. The approximate location of the full scenes and the area of interest used in the analysis are shown in figure 1 . The image dates and the perpendicular baselines at scene centre (relative to the earliest image) are shown in table 1.

$<<$ Table 1 here $>>$

\subsection{Data processing}

From the 32 images, 124 multilooked differential interferograms were generated, each with a perpendicular baseline of less than $200 \mathrm{~m}$ and having a time separation of no greater than 4 years. The multilooking window size used was $4 \times 20$ SLC pixels, resulting in pixels of approximately $100 \mathrm{~m} \times 100 \mathrm{~m}$ in ground range. Coherent points were identified as those having a coherence of at least 0.25 and unwrapping was performed using a reference point located in Coalville, on the East side of the Thringstone fault. This was based on the stable geology of the location and that, as the area is urban, it was likely to have a dense network of coherent points in each interferogram. The number of coherent points per row and column coordinate $(\mathrm{m})$ 
was calculated and a threshold value of $M=20$ was used, based primarily on the observation that over $60 \%$ of the image would be covered.

\subsection{ISBAS results}

Results using a standard SBAS algorithm are compared with the ISBAS results in figure 2. As discussed above, the SBAS velocities displayed are only for those for which the average coherence is greater than $0 \cdot 25$; the ISBAS velocities are shown for points for which 20 or more coherences greater than $0 \cdot 25$ are observed. For SBAS, the distribution of velocities is generally sparse (5162 points) and located primarily in urban locations; the ISBAS result is far more dense (35032 points) and widely distributed, almost covering the complete study area. The ISBAS results were most dense over urban areas but also provided velocities over agricultural fields, forests stands and also over some areas of water. The average ISBAS point velocity over all points is $0 \cdot 7 \mathrm{~mm}$ year $^{-1}$ with a standard deviation of $2 \cdot 4 \mathrm{~mm}$ year $^{-1}$. The maximum velocity of $11 \mathrm{~mm}$ year $^{-1}$ is found over the Swadlincote area. The variation in the standard deviation of the velocity over the area is shown in figure 2. As may be expected, smaller standard deviations occur in urban areas where the number of coherent pixels per point, $m_{i j}$, is likely to be high. Subsequently, there is a strong correlation between the variance and $m_{i j}$, indicating that the main source of error relates to the intermittent coherence of the target.

$<<$ Figure 2 here $>>$

The ISBAS velocities show a good spatial correlation to the coal measures of the area specifically showing uplift over former coal mining areas. Such a relationship has been noted in other areas (Bateson and Lawrence, 2012). The uplift is thought to be linked to rising mine water levels following the cessation of pumping of water from the mine sites.

A lozenge shaped area of uplift can be seen in the Swadlincote area of Derbyshire. Rates are up to around $10 \mathrm{~mm}$ year $^{-1}$ with faster rates of uplift in the north than in the south. The uplifting area closely matches the outcrop of middle coal measures. In the Coalville area where uplift is also observed, the relationship of the uplift to the coal measures is not as apparent as the coal measures dip under the overlying strata to the south. Both areas of uplift therefore overlay areas of underground mining which were abandoned in the early 1990s. At the time of abandonment, the ground water pumps used to stop the mines flooding were turned off therefore allowing the workings to flood and ground water levels to recover.

There is also a very strong spatial relationship between the areas of uplift and the faults in the area (see figure 2).

It is thought that uplift may be caused by one of two mechanisms: pore water pressure increase in response to the influx of ground water into areas that were previously drained, exerting a force on the rocks and causing them to swell; and reactivation of existing geological faults that may be the result of mine water lubricating the fault plane itself and making it easier for the fault plane to move. Alternatively the fault may re-activate to accommodate strain imposed on it as the pore water pressure increases. It is also possible that the fault acts as a constraint to the motion as it is a barrier to the migration of mine water and hence a barrier to the pore water increase related uplift.

\section{Conclusions}




\section{A. Sowter et al.}

A major limitation of long-time-series DInSAR is that the analysis is generally restricted to points that are of a consistently high coherence throughout the whole time series, meaning the spatial distribution of points is often inadequate to characterize a large-scale feature that persists across a range of land cover types. This paper presents a solution, the ISBAS method, that utilizes pixels that are intermittently coherent over time in addition to those that are consistently stable over all observations. The algorithm is based upon a minor modification of the wellestablished low-pass SBAS technique of Berardino et al. (2002) and generally results in a much better distribution of point velocity estimates, significantly improving the spatial sampling. The method has been applied to a sequence of ENVISAT images of the South Derbyshire and Leicestershire coalfield where the observed linear displacements are consistent with coal mining activity in the area and appear bound by the fault structures.

The purpose of this paper is to demonstrate the capability of ISBAS to derive a high density of linear velocities observations over a wide range of land cover classes. However, it is also possible to derive non-linear velocity components using a minor modification to the algorithm shown in Berardino et al. (2002). This would have the potential to show the time-dependent variations in land level that may be present, providing further information regarding the dynamics of the coal mines following closure. Although a future publication is planned in this topic, this is beyond the scope of this particular paper.

\section{Acknowledgements}

The ENVISAT data used in this paper was provided by the European Space Agency under Cat-1 project 3518. Luke Bateson, Poul Strange and Keith Ambrose published with permission of the Director of the British Geological Survey

\section{References}

Ambrose, K., McGrath, A., Weightman, G., Strange, P.J., Lattaway, S., LotT, G.K., BARRETt, D., DeAn, S. and Liddle, P., 2012, "Exploring the Landscape of The National Forest. A walkers' guide to the landscape and natural environment of The National Forest," British Geological Survey, Keyworth, Nottingham.

Bailey, M., Watson, I., Wyatt, L. and Davies, T., 2011, “Applications of pumping tests in the development of mine water management strategies and remediation schemes, Mine water - Managing the challenges," International Mine Water Association Proceedings, IMWA Aachen Germany. Rude, Freund and Wolkersdorfer (Editors), pp97-100.

BATESON, L. and LAWRENCE, D., 2012, “Terrafirma Interpretation report; Northumberland. Ground motion in an area of inactive mining," British Geological Survey Open Report OR/12/054.

BeKendam, R.F. and PotTGENS, J.J.E., 1995, "Ground movements over the coal mines in southern Limberg, The Netherlands, and their relation to rising mine waters,” Proceedings of the 5th International Symposium on Land Subsidence, the Hague, October 1995, IAHS, No. 234, pp3-12.

Berardino, P., Fornaro, G., LANARI, R. and SANSOSTI, E., 2002, “A new algorithm for surface deformation monitoring based on small baseline differential SAR interferograms,” IEEE Trans. Geosci. Remote Sens., 40(11), pp2375-2383. 
Biggs, J., Wright, T., Lu, Z. and Parsons, B., 2007, "Multi-interferogram method for measuring interseismic deformation: Denali Fault, Alaska,” Geophys. J. Int., 170, pp1165-1179.

Carney, J.N., Ambrose, K. and Brandon, A., 2001, "Geology of the country between Loughborough, Burton and Derby," Sheet Description of the British Geological Survey, Sheet 141 (England and Wales).

CARney, J.N., AmBrose, K., and BrandON, A., 2002, “Geology of the Loughborough district," Sheet Explanation of the British Geological Survey, Sheet 141 (England and Wales).

Donnelly, L.J., Culshaw, M.G., and Bell, F.G., 2007, “Longwall mining-induced fault reactivation and delayed subsidence ground movement in British Coalfields,” Quarterly Journal of Engineering Geology, October 2007, doi:10.1144/1470-9236.

Ferretti, A., Colesanti, C., Perissin, D., Prati, C. and Rocca, F., 2003, "Evaluating the effect of the observation time on the distribution of SAR permanent scatterers,” Proc. Fringe 2003, ESA-ESRIN, Frascati, Italy, 1-5 December 2003.

Lanari, R., Casu, F., Manzo, M., Zeni, G., Berardino, P., Manunta, M. and PePe, A., 2007, "An overview of the small baseline subset algorithm: A DInSAR technique for surface deformation analysis," Pure Appl. Geophys., 164, pp637-661.

OwEN, C., 1984, "The Leicestershire and South Derbyshire Coalfield, 1200-1900,” Moorland Publishing Company, Ashbourne, Derbyshire, 321p.

PotTGENS, J.J.E., 1985, "Uplift as a result of rising mine waters." In: The Development Science and Art of Mineral Surveying, Proceedings of the 6th International Congress. International Society for Mine Surveying, Harrogate UK, 2, pp928-938.

SMITH, J.A., 1996. "Groundwater Rebound in the Leicestershire Coalfield,” Journal of Chartered Institution of Water and Environmental Management (CIWEM), 10, pp280-289.

Strange, P.J., Carney, J.N., and Ambrose, K., 2010, "Geology of the Coalville District - a brief explanation of the geological map," Sheet Explanation of the British Geological Survey. 1:50 000 Sheet 155 Coalville (England and Wales). 38p.

WorssAM, B.C. and OLD, R.A., 1988, “Geology of the country around Coalville,” Memoir of the British Geological Survey, Sheet 155 (England and Wales). 
A. Sowter et al.

\begin{tabular}{llll}
\hline Date & $\boldsymbol{B}_{1}(\mathrm{~m})$ & Date & $\boldsymbol{B}_{1(\mathrm{~m})}$ \\
\hline 28 June 2003 & 0 & 9 December 2006 & 690 \\
20 December 2003 & 94 & 13 January 2007 & 1078 \\
8 May 2004 & -355 & 17 February 2007 & 257 \\
12 June 2004 & 502 & 28 April 2007 & 173 \\
17 July 2004 & 469 & 7 July 2007 & 368 \\
21 August 2004 & 330 & 11 August 2007 & 317 \\
30 October 2004 & 567 & 24 November 2007 & 575 \\
8 January 2005 & -625 & 2 February 2008 & 546 \\
10 September 2005 & 203 & 8 March 2008 & 188 \\
19 November 2005 & 755 & 21 June 2008 & 552 \\
13 May 2006 & 264 & 30 August 2008 & 598 \\
17 June 2006 & 433 & 4 October 2008 & 271 \\
22 July 2006 & 1034 & 8 November 2008 & 488 \\
26 August 2006 & 994 & 13 December 2008 & 40 \\
30 September 2006 & -347 & 17 January 2009 & 649 \\
4 November 2006 & -213 & 21 February 2009 & 340 \\
\hline
\end{tabular}

Table 1. ENVISAT ASAR Image dates and perpendicular baselines. $\boldsymbol{B}_{1}$ is the perpendicular baseline relative to the first image acquisition on 28 June 2003. 

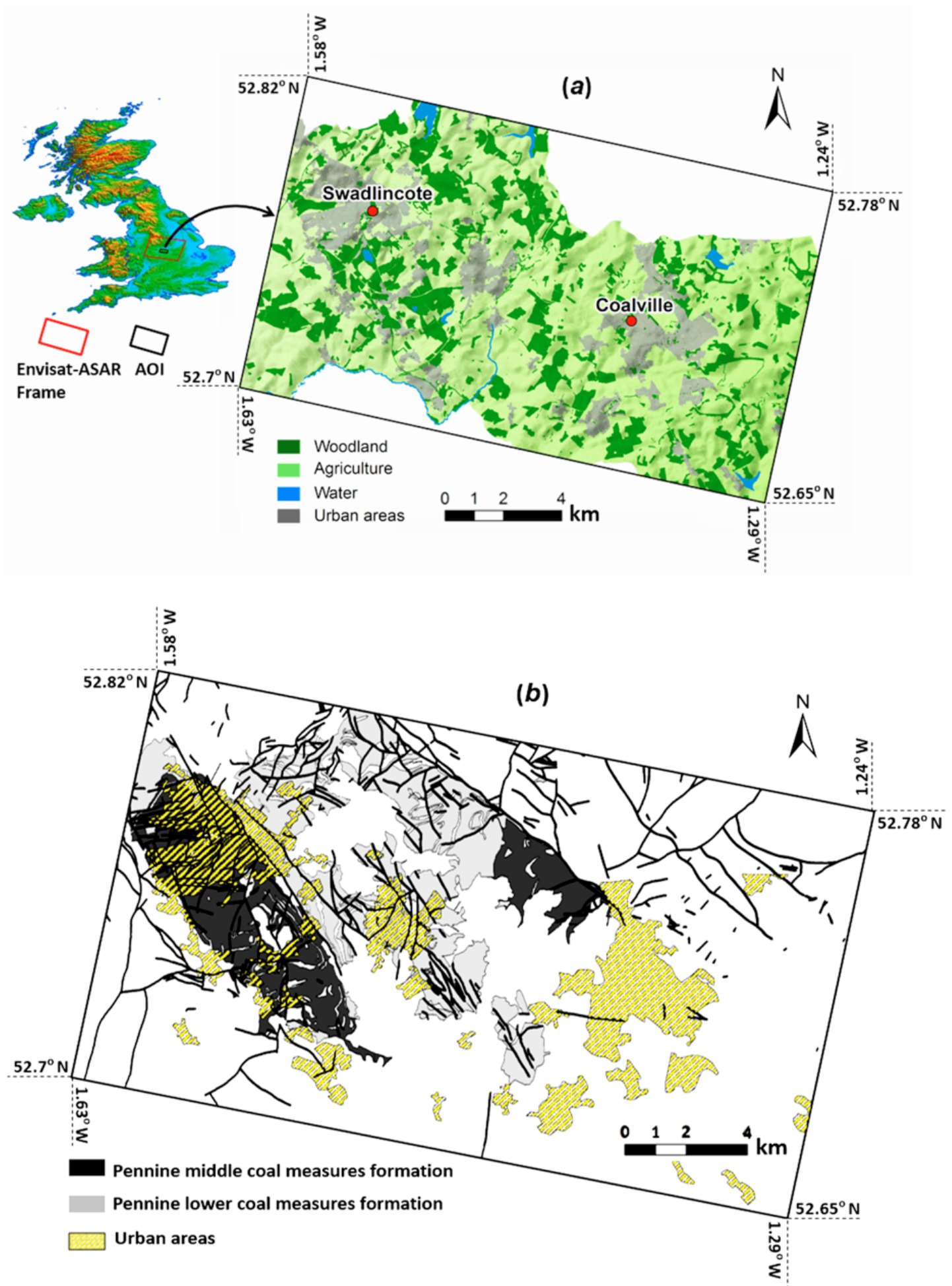

Figure 1. (a) A detail map locating the ENVISAT ASAR image frame and the area of interest (AOI) within the UK (top left) and a land cover map (top right). The area has only a small amount of urban cover, which includes the locations of the main towns of Swadlincote and Coalville. Details of the coal measures and the major faults within the area are shown in $(b)$. 


\section{A. Sowter et al.}

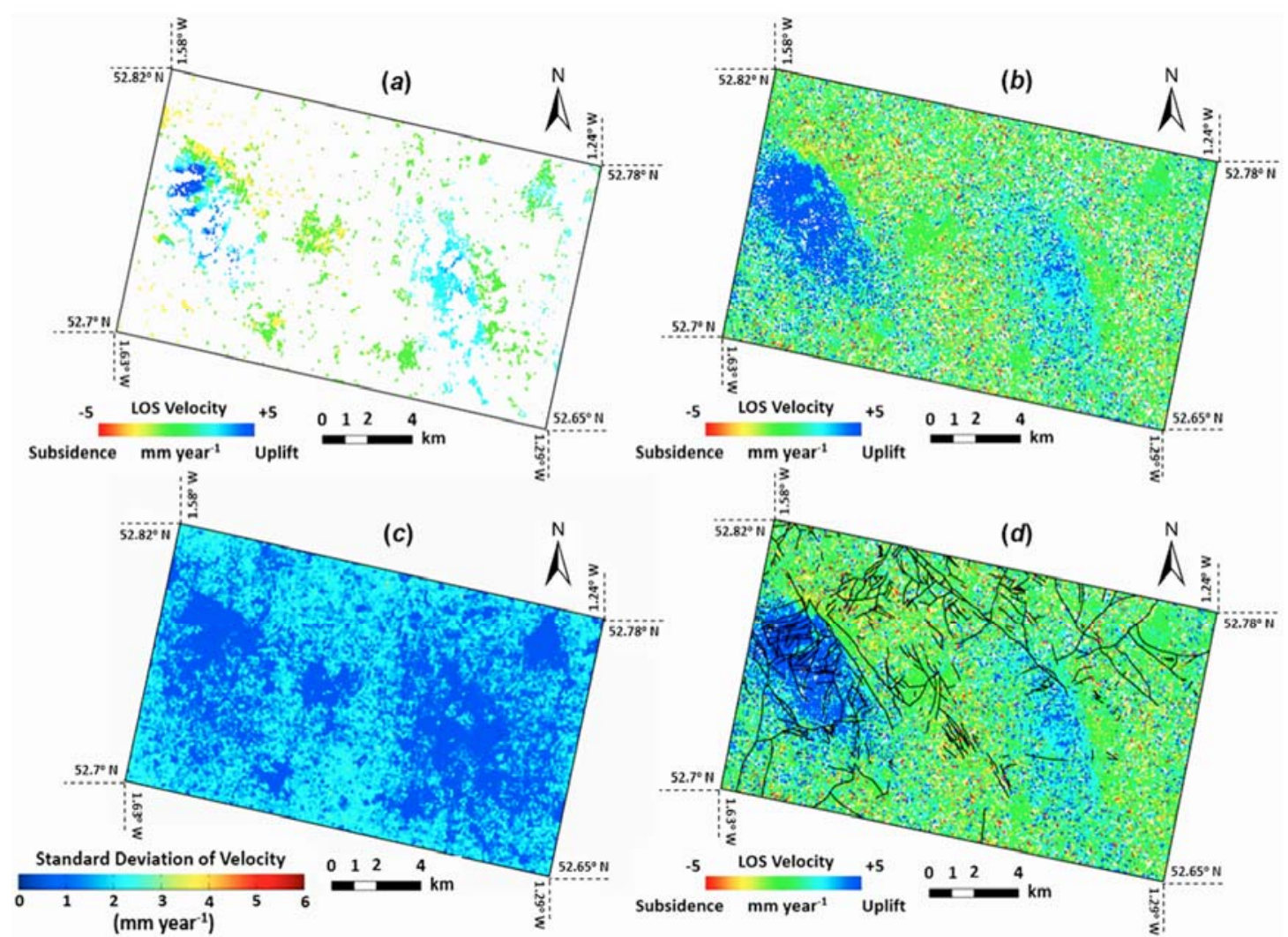

Figure 2. The line-of-sight (LOS) velocities derived following $(a)$ a standard SBAS and $(b)$ an ISBAS analysis. Each point covers an area of approximately $100 \mathrm{~m} \times$ $100 \mathrm{~m}$ on the ground. $(c)$ illustrates the standard deviations of the velocities and $(d)$ shows the ISBAS point velocities of the area with faults overlaid. 